\title{
PLACKETT-BURMAN DESIGN AS A TOOL FOR SCREENING AND PROCESS OPTIMIZATION OF RIVASTIGMINE-LOADED LIPID NANOCARRIERS
}

\author{
ANUBHAV ANAND ${ }^{1 *}$, GYANENDRA SINGH ${ }^{2}$, SHUBHINI A SARAF $^{3}$
}

${ }^{1}$ School of Pharmacy, Babu Banarasi Das University, BBD City, Lucknow, Uttar Pradesh, India. ${ }^{2}$ Department of Pharmaceutics, IIT-BHU, Varanasi, Uttar Pradesh, India. ${ }^{3}$ Department of Pharmaceutical Sciences, Babasaheb Bhimrao Ambedkar University, Vidya Vihar, Lucknow, Uttar Pradesh, India. Email: anubhavanand2000@gmail.com

Received: 30 June 2018, Revised and Accepted: 23 July 2018

ABSTRACT

Objective: Plackett-Burman experimental design is used to identify the most important factors early in the experimentation phase when complete knowledge about the system is usually unavailable. The objective of this study was to screen out the most important factors affecting the size and entrapment efficiency of rivastigmine hydrogen tartrate (RHT) nanostructured lipid carriers (NLCs).

Methods: The RHT-loaded NLC was prepared by the modified solvent emulsification-diffusion method. The independent variables selected for Plackett-Burman design were drug: lipid ratio, solid lipid/liquid lipid (S/L) ratio, concentration Ryoto sugar ester (\%w/v), the concentration of poloxamer $188(\% \mathrm{w} / \mathrm{v})$, sonication time $(\mathrm{min})$, sonication amplitude, and stirring time (h).

Results: The $\mathrm{R}^{2}$ value for the particle size equation was $86.16 \%$. p value was $(<0.05) 0.048$ in case of sonication time. In case of entrapment efficiency, the $\mathrm{R}^{2}$ value was $87.12 \%$. The $\mathrm{p}$ value $(\mathrm{p}<0.05)$ for $\mathrm{S} / \mathrm{L}$ ratio and the Ryoto sugar $(\% \mathrm{w} / \mathrm{v})$ was 0.028 and 0.042 , respectively.

Conclusion: It can be concluded that sonication time has a significant effect on particle size, whereas S/L ratio and Ryoto sugar ester concentration have a significant effect on entrapment efficiency.

Keywords: Plackett-Burman, Rivastigmine, Nanostructured lipid carrier.

(C) 2018 The Authors. Published by Innovare Academic Sciences Pvt Ltd. This is an open access article under the CC BY license (http://creativecommons. org/licenses/by/4. 0/) DOI: http://dx.doi.org/10.22159/ajpcr.2018.v11i12.28066

\section{INTRODUCTION}

Micro- and nano-drug delivery systems are developed to deliver the drug to desired tissue in human body, especially to a specific area or organ in a more stable and controlled way [1]. Nanotechnologies are beginning to change the scientific landscapes in terms of disease diagnosis, treatment [2]. All together to conquer these issues, a lot of hope has been centered on lipid-based carriers, for example, nanoemulsions (NEs) and nanostructured lipid carriers (NLCs) [3]. Nanoformulations are now continuously being researched for superior absorption, higher bioavailability, and greater therapeutic efficacy. Lipid-based nanoformulations have found much preference with the formulation scientist due to their relatively higher safety profile and enhancement of bioavailability [4]. Solid lipid nanoparticles (SLNs) and NLC have been introduced as potential attractive and marketable options due to their natural components [5]. The potential drawbacks of SLNs, such as limited drug loading capacity and drug expulsion during storage, can be avoided by the modifications that have been envisaged in NLCs [6]. In contrast to SLN, NLC is formed by controlling mixing of solid lipids with spatially incompatible liquid lipids. The incorporation of spatially incompatible liquid lipids to solid lipids leads larger distance between the fatty acid chain of the glycerides and general imperfection in the crystal [7]. This imperfect crystallization results in improved drug loading capacity and stable drug incorporation during storage [8]. The small size of the lipid particles ensures close contact with stratum corneum (SC)/membrane and can increase the amount of drug penetrating into mucosa or skin [9]. To resolve the experimental variables and interactions that have a major influence on the result with minimum possible runs and to determine the factors which would affect the quality of the product, a screening experiment was envisaged. In 1946, Plackett and Burman published a paper titled "the design of optimal multifactorial experiments" in Biometrika [10]. PlackettBurman design is a very competent screening design when only the major factors affecting the required output are to be considered. The Plackett-Burman design is superior to other screening designs, i.e., the fractional factorial design, the main effects are orthogonal and twofactor interactions are partly confounded to the main effects. The aim of the present work was to find out the major variables that affect the particle size of NLC and entrapment efficiency of rivastigmine hydrogen tartrate in NLC (RHT-NLC).

\section{MATERIALS AND METHODS}

\section{Materials}

RHT was received as a gift sample from Torrent Pharmaceutical Ltd. (Mehsana, Gujarat, India). Compritol 888 ATO was a gift sample from Gattefosse Pvt. Ltd. (Mumbai, India). Ryoto sugar ester S-1670 was also a gift sample from Mitsubishi-Kagaku Foods Corporation (Tokyo, Japan). Triacetin was procured from SD Fine Chem Ltd., Mumbai, India. All other reagents were of analytical category and obtained from local commercial sources.

\section{Solubility analysis}

The saturation solubility of the drug was determined separately by adding an excess amount of drug to $2 \mathrm{~mL}$ each of the following oils triacetin, sesame oil, isopropyl myristate, canola oil, almond oil in tightly closed vials. The solutions were agitated for $24 \mathrm{~h}$ on a rotary shaker. The samples were centrifuged at $5000 \mathrm{rpm}$ for $15 \mathrm{~min}$ and diluted appropriately to analyze the drug content through HPLC (Shimadzu, Millennium Column $125 \mathrm{~mm} \times 4.6 \mathrm{~mm}$, mobile phase acetonitrile: buffer).

\section{Preparation of NLC}

A modified solvent emulsification-diffusion method was used for the preparation of NLC [11]. Solid lipid (Compritol 888 ATO) and liquid lipid (triacetin) were dissolved in 1:1 ethanol: chloroform mixture $(2 \mathrm{~mL})$ as the internal phase. The RHT ( $5 \mathrm{mg}$ ) was added to the above organic solvent 
mixture. A lipid solution containing drug was dispersed gradually in the aqueous solution of sucrose stearate (Ryoto sugar ester S-1670, $8 \mathrm{~mL}$ ) and sonicated (Ultrasonicator - Sartorius, Labsonic P, 3 sec interval). Thus, prepared primary emulsion was dispersed into aqueous poloxamer 188 solutions as a surfactant and stirred to remove the organic solvent from the continuous phase. The dispersion was centrifuged (18,000 RPM for $20 \mathrm{~min})$ using Sartorius, Sigma 3-18K (Germany) to separate the RHT-NLCs. Thus, obtained NLCs were redispersed in an aqueous solution of Poloxamer $188(1 \% \mathrm{w} / \mathrm{v})$ and sonicated to get the RHT-NLCs.

\section{Plackett-Burman design}

The screening of factors was made with the help of Plackett-Burman design using Minitab 17. To screen out critical independent factors from among several factors, a few were shortlisted.

These variables were screened with 12 runs as per Plackett-Burman design (Table 1). Two levels of independent variables (high and low) were selected based on literature. Mean particle size and entrapment efficiency were selected as dependent variables.

\section{$Y=A o+A 1 X 1+A 2 X 2+A 3 X 3+A 4 X 4+A 5 X 5+A 6 X 6+A 7 X 7$}

Where, $\mathrm{Y}$ is the response, $\mathrm{A} 0$ is a constant, and $\mathrm{A} 1-\mathrm{A} 7$ are the coefficients of the response values (Tables 2 and 3).

\section{Particle size}

The particle size of RHT-NLCs was examined by photon correlation spectroscopy, in which light scattering fluctuations due to the Brownian movement were analyzed at a temperature of $25 \pm 1^{\circ} \mathrm{C}$ and a scattering angle of $90^{\circ}$ using Zetasizer 1000 HS (Malvern Instruments, UK)

\section{Entrapment efficiency}

A fixed quantity (10 mL) of RHT-NLCs dispersion was centrifuged $(18,000 \mathrm{RPM}$ for $20 \mathrm{~min})$. The supernatant was separated and analyzed for quantifying unencapsulated drug by HPLC. For the determination of the amount of drug in the sample, chromatographic separations were performed using HPLC (Shimadzu LC2010 CHT HPLC, Tokyo, Japan), which was equipped with Lichrospher reversed-phase C18 column (125 mm $\times 4.6 \mathrm{~mm}$, pore size $5 \mu \mathrm{m}$ ). The mobile phases consisted of acetonitrile: ammonium phosphate (monobasic) buffer pH 5.6 (16:84 v/v). The flow rate was fixed at $1.0 \mathrm{~mL} / \mathrm{min}$ and $\lambda_{\text {max }}$ was set at $217 \mathrm{~nm}$. The drug entrapment efficiency (\%) was computed using the following equation:

Entrapmentefficiency $=\frac{\mathrm{Wt}-\mathrm{Ws}}{\mathrm{Wt}} \times 100$

Where, $W_{t}$ is initial weight and was being weighted, of the drug in the supernatant.

\section{RESULTS AND DISCUSSION}

RHT is soluble in water, methanol, and ethanol, the pKa value is 8.85 (strong base). The solubility of RHT was determined in various oils such as triacetin, sesame oil, isopropyl myristate, canola oil, and almond oil. The maximum solubility of RHT was found in triacetin. It is the triester of glycerol and acetylating agents (acetic acid and acetic anhydride). It is a colorless, viscous, and odorless liquid. Triacetin is soluble (in water) and an extremely weak basic (essentially neutral) compound (based on its pKa) [12]. Higher solubility of RHT in triacetin may be attributed to strong basic nature of RHT (Fig. 1).

RHT-NLCs were prepared by the modified solvent emulsificationdiffusion method. The particle size of the prepared formulation was found to vary between 218 and $458 \mathrm{~nm}$. The particle size is very critical to the formulation of the nanoparticles. It determines the biological fate, toxicity, and targeting ability of this delivery system [13]. In addition, it can influence drug loading, drug release in vivo distribution, and stability of nanoparticles. The $\mathrm{R}^{2}$ value for particle size was found to be $86.16 \%$. Sonication is the act of applying sound energy to agitate

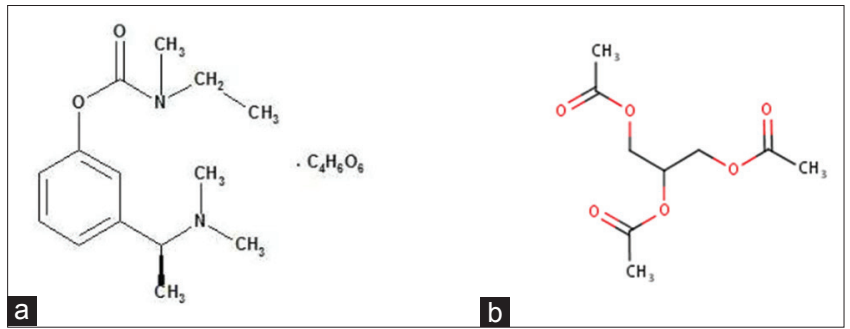

Fig. 1: Chemical structure of (a) rivastigmine hydrogen tartrate and (b) triacetin

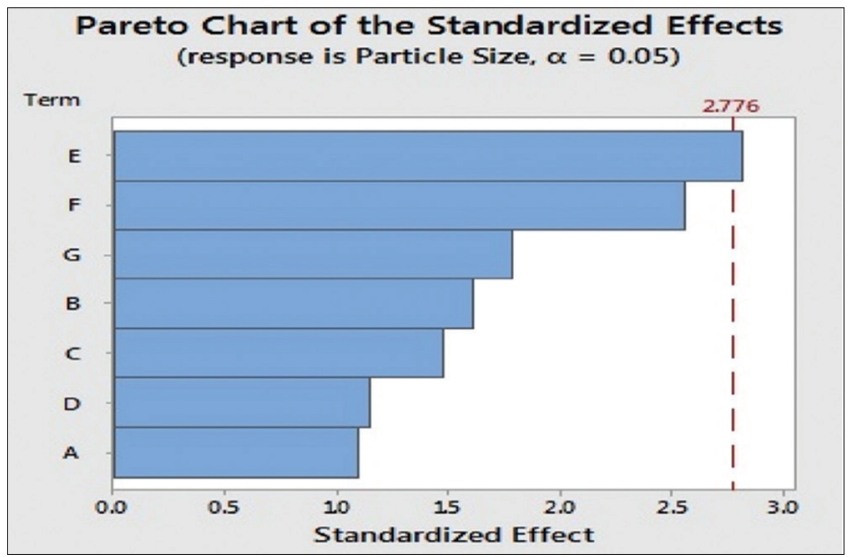

Fig. 2: Pareto chart of the standardized effect of various factors on particle size, (A) drug: lipid ratio, (b) solid lipid/liquid lipid ratio, (c) Ryoto sugar ester (\%w/v), (d) poloxamer $188(\% \mathrm{w} / \mathrm{v})$, (e) sonication time ( $\mathrm{min}$ ), (f) sonication amplitude, (g) stirring time (h)

Table 1: The coded value of 1 and -1 as high and low values independent variables for Plackett-Burman design

\begin{tabular}{|c|c|c|c|c|c|c|c|}
\hline Run & $\begin{array}{l}\text { Value of drug: lipid } \\
\text { ratio }\end{array}$ & $\begin{array}{l}\text { Value of solid: liquid } \\
\text { lipid }\end{array}$ & $\begin{array}{l}\text { Sucrose } \\
\text { ester }(\% w / v)\end{array}$ & $\begin{array}{l}\text { Poloxamer } \\
188(\% \mathrm{w} / \mathrm{v})\end{array}$ & $\begin{array}{l}\text { Sonication } \\
\text { time (min) }\end{array}$ & $\begin{array}{l}\text { Sonication } \\
\text { amplitude }\end{array}$ & $\begin{array}{l}\text { Stirring } \\
\text { time (h) }\end{array}$ \\
\hline 1 & 1 & -1 & 1 & -1 & -1 & -1 & 1 \\
\hline 2 & 1 & 1 & -1 & 1 & 1 & -1 & 1 \\
\hline 3 & -1 & -1 & -1 & -1 & -1 & -1 & -1 \\
\hline 4 & -1 & -1 & -1 & 1 & 1 & 1 & 1 \\
\hline 5 & -1 & 1 & -1 & -1 & -1 & 1 & 1 \\
\hline 6 & -1 & -1 & 1 & 1 & 1 & -1 & 1 \\
\hline 8 & 1 & -1 & 1 & 1 & -1 & 1 & -1 \\
\hline 9 & -1 & 1 & 1 & 1 & -1 & 1 & 1 \\
\hline 10 & -1 & 1 & 1 & -1 & 1 & -1 & -1 \\
\hline 11 & 1 & 1 & -1 & 1 & -1 & -1 & -1 \\
\hline 12 & 1 & -1 & -1 & -1 & 1 & 1 & 1 \\
\hline
\end{tabular}


particles in a sample. Ultrasonication $(>20 \mathrm{KHz})$ is a very valuable processing method in the production and application of nanosized materials. In general, ultrasonic cavitations increase polymerization and depolymerization reactions by momentarily dispersing a mass, increasing emulsification rates; improving diffusion rates; and producing greatly concentrated emulsions or uniform dispersions of micronized or nanosized materials. Sonication was done at $3 \mathrm{~s}$ interval because if sonication is continued without interruption for long periods of time, larger particles are reformed [14]. p value was established to be $(p<0.05) 0.048$ in case of sonication time, but for other factors, it was more than 0.05 (Fig. 2) which indicates that sonication time has a significant effect on particle size. The minimum particle size was found at $5 \mathrm{~min}$ of sonication time. It may be attributed to the aggregation of particles because the sufficient surfactant concentration was not available to form a protective layer on each nanoparticle [15].

Particle size $=95-368$ drug lipid ratio +9.08 solid lipid: Liquid lipid ratio -49.8 ryoto sucrose stearate (\% w/v) -38.8 poloxamer $188(\% \mathrm{w} / \mathrm{v})+19.10$ sonication time +1.737 sonication amplitude +30.1 stirring time

In case of entrapment efficiency, the $\mathrm{R}^{2}$ value was found to be $87.12 \%$. $\mathrm{p}$ value $(<0.05)$ for solid lipid: Liquid lipid $(\mathrm{S} / \mathrm{L})$ ratio and Ryoto sugar $(\% \mathrm{w} / \mathrm{v})$ was 0.028 and 0.042 , respectively, which clearly indicates that both factors affect the entrapment efficiency significantly (Fig. 3).

Table 2: Actual values of minimum and maximum levels of various factors

\begin{tabular}{llll}
\hline \multirow{2}{*}{ Factors } & Unit & \multicolumn{2}{l}{ Levels } \\
\cline { 3 - 4 } & & $\mathbf{- 1}$ & $\mathbf{+ 1}$ \\
\hline Value of drug: lipid ratio & - & 0.1 & 0.2 \\
Value of solid: liquid lipid & - & 3 & 9 \\
Sucrose ester $(\% \mathrm{w} / \mathrm{v})$ & $\% \mathrm{w} / \mathrm{v}$ & 0.5 & 1.5 \\
Poloxamer $188(\% \mathrm{w} / \mathrm{v})$ & $\% \mathrm{w} / \mathrm{v}$ & 0.25 & 1.25 \\
Sonication time & Min & 5 & 10 \\
Sonication amplitude & - & 50 & 100 \\
Stirring time & $\mathrm{h}$ & 1 & 3 \\
\hline
\end{tabular}

Table 3: Solubility of RHT in various oils

\begin{tabular}{ll}
\hline Oil & Solubility $(\mathbf{m g} / \mathbf{m L})$ \\
\hline Triacetin & $21.46 \pm 1.07$ \\
Sesame oil & $5.083 \pm 1.34$ \\
Isopropyl myristate & $5.20 \pm 0.42$ \\
Canola oil & $4.22 \pm 1.1$ \\
Almond oil & $3.79 \pm 0.92$ \\
\hline
\end{tabular}

Liquid lipid is included in the NLC to increase the solubility of drug which, in turn, increases the entrapment of drug and avoids leakage. Sucrose esters are natural surfactant used as a penetration enhancer and controlled release matrix [16]. In the present study, Ryoto sucrose ester functions as a surfactant which helps in solubilizing the drug in lipid and dispersing the lipids in an aqueous solution to form a stable nanodispersion. As shown in Table 4, the highest entrapment efficiency was found in the case of the highest surfactant concentration. In most studies, a higher surfactant concentration leads to a smaller particle size and lower entrapment efficiency, but in this case, a higher solubilizing effect may have led to higher entrapment since Ryoto sucrose ester was used to solubilize the drug in lipid and to form a primary emulsion.

Entrapment efficiency $=40.9-15.0$ drug lipid ratio +2.139 solid lipid: Liquid lipid ratio +11.17 sucrose stearate (\%) -7.83 poloxamer 1881.167 sonication time -0.0233 sonication amplitude -0.25 stirring time

\section{CONCLUSION}

To find out critical parameters for preparation of stable NLCs, Plackett-Burman design was applied. The parameters that may affect the formulation were selected on the basis of a literature review. The study suggests the significance of controlling the critical formulation and process parameters during formulation as they

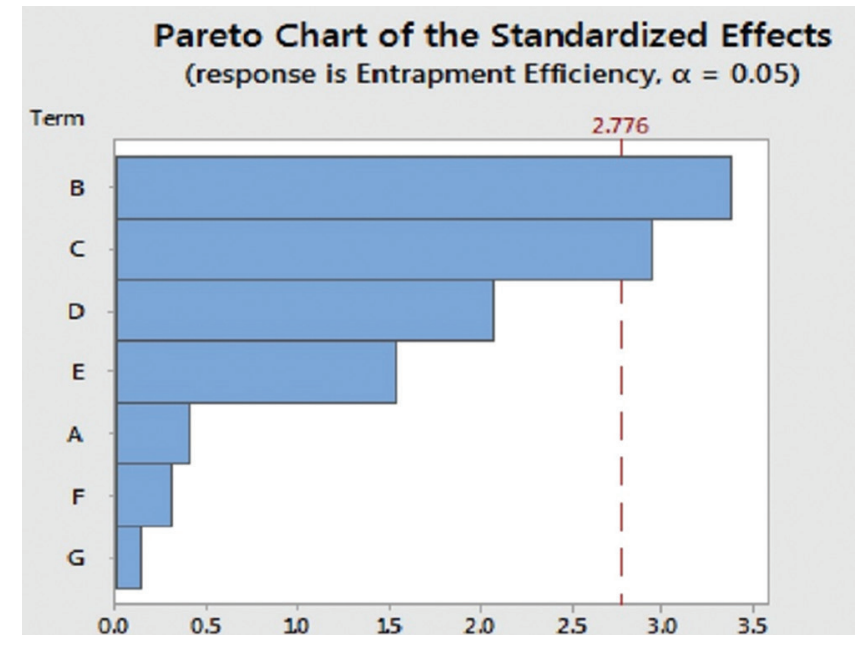

Fig. 3: Pareto chart of the standardized effect of various factors on entrapment efficiency, (a) drug: lipid ratio, (b) S/L ratio, (c) Ryoto sugar ester (\%w/v), (d) poloxamer $188(\% \mathrm{w} / \mathrm{v})$, (e) sonication time (min), (f) sonication amplitude, (g) stirring time (h)

Table 4: Values of the dependent variable of all the RHT-NLC formulations

\begin{tabular}{|c|c|c|c|c|c|c|c|c|c|}
\hline $\begin{array}{l}\text { Formulation } \\
\text { number }\end{array}$ & $\begin{array}{l}\text { Value of } \\
\text { drug: lipid } \\
\text { ratio }\end{array}$ & $\begin{array}{l}\text { Value of solid } \\
\text { lipid: Liquid } \\
\text { lipid ratio }\end{array}$ & $\begin{array}{l}\text { Ryoto sugar } \\
\text { concentration } \\
(\% \mathrm{w} / \mathrm{v})\end{array}$ & $\begin{array}{l}\text { Poloxamer } \\
188 \\
\text { concentration } \\
(\% \mathrm{w} / \mathrm{v})\end{array}$ & $\begin{array}{l}\text { Sonication } \\
\text { time (min) }\end{array}$ & $\begin{array}{l}\text { Sonication } \\
\text { amplitude }\end{array}$ & $\begin{array}{l}\text { Stirring } \\
\text { time (h) }\end{array}$ & $\begin{array}{l}\text { Particle } \\
\text { size (nm) }\end{array}$ & $\begin{array}{l}\text { Entrapment } \\
\text { efficiency } \\
(\%)\end{array}$ \\
\hline 1 & 0.2 & 3 & 1.5 & 0.25 & 5 & 50 & 3 & $218 \pm 2.36$ & $56.35 \pm 1.64$ \\
\hline 2 & 0.2 & 9 & 0.5 & 1.25 & 10 & 50 & 3 & $439 \pm 5.25$ & $37.4 \pm 2.15$ \\
\hline 3 & 0.1 & 3 & 0.5 & 0.25 & 5 & 50 & 1 & $329 \pm 3.34$ & $42.83 \pm 1.09$ \\
\hline 4 & 0.1 & 3 & 0.5 & 1.25 & 10 & 100 & 1 & $388 \pm 2.93$ & $32.16 \pm 1.36$ \\
\hline 6 & 0.1 & 3 & 1.5 & 1.25 & 10 & 50 & 3 & $319 \pm 1.40$ & $36.67 \pm 2.01$ \\
\hline 7 & 0.2 & 9 & 1.5 & 0.25 & 10 & 100 & 1 & $449 \pm 4.31$ & $59.10 \pm 1.30$ \\
\hline 8 & 0.2 & 3 & 1.5 & 1.25 & 5 & 100 & 1 & $218 \pm 1.38$ & $36.18 \pm 1.25$ \\
\hline 9 & 0.1 & 9 & 1.5 & 1.25 & 5 & 100 & 3 & $412 \pm 2.48$ & $62.47 \pm 1.60$ \\
\hline 10 & 0.1 & 9 & 1.5 & 0.25 & 10 & 50 & 1 & $328 \pm 3.19$ & $59.27 \pm 1.38$ \\
\hline 11 & 0.2 & 9 & 0.5 & 1.25 & 5 & 50 & 1 & $201 \pm 1.37$ & $48.49 \pm 1.27$ \\
\hline 12 & 0.2 & 3 & 0.5 & 0.25 & 10 & 100 & 3 & $458 \pm 4.16$ & $34.16 \pm 1.36$ \\
\hline
\end{tabular}


significantly influenced the final product, such as particle size and drug encapsulation efficiency. On the basis of the result, it can be concluded that for RHT-NLC the critical parameters were sonication time, S/L ratio, and Ryoto sugar ester (surfactant) concentration. Sonication time affects the particle size of NLC, whereas S/L ratio and Ryoto sugar ester concentration affect the entrapment efficiency of the formulation. Plackett-Burman design is a suitable screening method which can be utilized for other similar studies as well.

\section{AUTHORS' CONTRIBUTION}

Shubhini A. Saraf - Concept, planning, and overall supervision. Gyanendra Singh - Contributed in design of experiment. Anubhav Anand - Planning and execution.

\section{CONFLICTS OF INTEREST}

The authors declare that they have no conflicts of interest.

\section{REFERENCES}

1. Hemant K, Raizaday A, Sivadasu P, Uniyal S, Kumar SH. Cancer nanotechnology: Nanoparticulate drug delivery for the treatment of cancer. Int J Pharm Pharm Sci 2015;7:40-6.

2. Deore S, Shahi SR, Dabir P. Nanoparticle: As targeted drug delivery system for depression. Int J Curr Pharm Res 2016;8:7-11.

3. Gardouh AR, Faheim SH, Nouh AT, Ghorab MM. Influence of formulation factors on the size of nanostructured lipid carriers and nanoemulsions prepared by high shear homogenization. Int J Pharm Pharm Sci 2018;10:61-75.

4. Gupta R, Agarwal A, Anjum MM, Dwivedi H, Kymonil KM, Saraf SA. Lipid nanoformulations for oral delivery of bioactive: An overview. Curr Drug Ther 2014;9:35-46.
5. Naseri N, Valizadeh H, Zakeri-Milani P. Solid lipid nanoparticles and nanostructured lipid carriers: Structure, preparation and application. Adv Pharm Bull 2015;5:305-13.

6. Fang CL, Al-Suwayeh SA, Fang JY. Nanostructured lipid carriers (NLCs) for drug delivery and targeting. Recent Pat Nanotechnol 2013;7:41-55.

7. Jia LJ, Zhang DR, Li ZY, Feng FF, Wang YC, Dai WT, et al. Preparation and characterization of silybin-loaded nanostructured lipid carriers. Drug Deliv 2010;17:11-8.

8. Sarangi MK, Padhi S. Solid lipid nanoparticles-a review. J Crit Rev 2016;3:5-12.

9. Plackett RL, Burman JP. The design of the optimal multifactorial experiment. Biometrika 1946;33:305-25.

10. Mohan DC, Suresh A, Mukundan S, Gupta S, Viswanad V. Development and in vitro evaluation of nanolipid carriers of clobetasol propionate and pramoxine hydrochloride for topical delivery. Int J App Pharm 2018;10:28-36.

11. Anand A, Arya M, Singh G, Kaithwas G, Saraf SA. Design and development of resveratrol NLCs and their role in the synaptic transmission of acetylcholine in C. Elegans model. Curr Drug Ther 2017; $12: 134-48$

12. Pubchem. Triacetin. Available from: https://www.pubchem.ncbi.nlm. nih.gov/compound/5541. [Last cited on 2018 Jun 21].

13. Singh R, Lillard JW Jr. Nanoparticle-based targeted drug delivery. Exp Mol Pathol 2009;86:215-23.

14. Al-Kaysi RO, Müller AM, Ahn TS, Lee S, Bardeen CJ. Effects of sonication on the size and crystallinity of stable zwitterionic organic nanoparticles formed by reprecipitation in water. Langmuir 2005;21:7990-4.

15. Singh AP, Saraf SK, Saraf SA. SLN approach for nose-to-brain delivery of alprazolam. Drug Deliv Transl Res 2012;2:498-507.

16. Szüts A, Szabó-Révész P. Sucrose esters as natural surfactants in drug delivery systems-a mini-review. Int J Pharm 2012;433:1-9. 